\title{
MicroRNA-33a promotes cell proliferation and inhibits apoptosis by targeting PPAR $\alpha$ in human hepatocellular carcinoma
}

\author{
${\text { WEIPING } \mathrm{CHANG}^{1 *}, \text { LEI ZHANG }}^{1^{*}}$, YAO XIAN $^{2}$ and $\mathrm{ZHAOXIANG} \mathrm{YU}^{1}$ \\ ${ }^{1}$ Department of General Surgery, The First Affiliated Hospital of Xi'an Medical University, Xi'an, Shaanxi 710077; \\ ${ }^{2}$ Department of Nutrition, The First Affiliated Hospital of Xi'an Jiaotong University, Xi'an, Shaanxi 710061, P.R. China
}

Received August 12, 2016; Accepted January 20, 2017

DOI: $10.3892 /$ etm.2017.4236

\begin{abstract}
MicroRNA-33a (miR-33a) is dysregulated in a number of human cancers, where it functions as an oncogenic miRNA. However, the clinical significance of miR-33a and its underlying molecular pathways regarding the progression of hepatocellular carcinoma (HCC) are currently unknown. In the present study, it was observed that the level of miR-33a expression was significantly increased in HCC tissues, relative to adjacent non-tumor tissues. Increased miR-33a expression was significantly correlated with poor prognostic features of HCC, including larger tumor size, higher Edmondson-Steiner grading and higher tumor-node-metastasis tumor stage. Furthermore, high levels of miR-33a expression were associated with decreases in the 5-year overall survival rate and recurrence-free survival of patients with HCC. In addition, functional experiments indicated that overexpression of miR-33a led to increased proliferation and reduced apoptosis of the HCC cell line Huh7, while knockdown of miR-33a decreased proliferation and induced apoptosis in the HCC cell line HepG2. Furthermore, peroxisome proliferator activated receptor alpha (PPAR $\alpha)$ was identified as a direct target of miR-33a in HCC. Upregulation of miR-33a was found to reduce the levels of PPAR $\alpha$ expression in Huh7 cells, while inhibition of miR-33a lead to a downregulation in PPAR $\alpha$ expression in HepG2 cells. Collectively, these results suggest that miR-33a regulates the proliferation and apoptosis of $\mathrm{HCC}$ cells, and is a potential prognostic marker of HCC.
\end{abstract}

\section{Introduction}

MicroRNAs (miRNAs) are an endogenous group of small (18-25 nucleotides), non-coding RNA molecules which serve

Correspondence to: Dr Zhaoxiang Yu, Department of General Surgery, The First Affiliated Hospital of Xi'an Medical University, 48 Fenghao West Road, Xi'an, Shaanxi 710077, P.R. China E-mail: yuzhaoxiang_jgsy@163.com

${ }^{*}$ Contributed equally

Key words: microRNA-33a, hepatocellular carcinoma, proliferation, apoptosis, peroxisome proliferator activated receptor alpha key roles as post-transcriptional regulators by binding to the 3'-untranslated region (3'UTR) of target mRNA (1). Recent results indicate that miRNAs may modulate numerous cellular processes, including differentiation, proliferation, apoptosis and migration (2). Thus, miRNAs are considered to be potential regulators in the development and progression of various human diseases, including cardiovascular disease, diabetes and cancer (3-5).

Hepatocellular carcinoma (HCC) is among the most severe forms of human cancer and is the third-leading cause of cancer-related mortality worldwide (6). Although treatments for HCC have improved, the long-term prognosis for patients with HCC remains poor, with a current 5-year survival rate of $30 \%(7,8)$. A lack of biomarkers for early diagnosis and effective therapeutic targets are primary reasons for the poor disease outcomes. Therefore, studies into the molecular mechanisms of HCC pathogenesis are warranted, in order to identify potential biomarkers and therapeutic targets of HCC $(9,10)$. Recently, the roles of miRNAs in HCC have been investigated, with results indicating that the expression and/or function of miRNAs become aberrant in the pathogenesis of HCC (7).

miR-33a is a member of the highly conserved miR-33 family and is an intronic miRNA located within the genes of sterol regulatory element-binding proteins $(11,12)$, where it principally regulates the metabolism of cholesterol (13) and glucose (14). In addition to its functional roles in metabolism, miR-33a has been implicated in a number of human cancers. In pancreatic ductal adenocarcinoma, it has been observed that miR-33a exerts tumor suppressive effects, by modulating the growth, apoptosis, epithelial-to-mesenchymal transition and chemoresistance of pancreatic cancer cells $(15,16)$. Similarly, a previous study in lung cancer demonstrated that miR-33a had inhibitory effects on the metastasis of cancer cells towards bone tissue (17). It has also been observed in glioma cancer that miR-33a promotes the growth and self-renewal of glioma-initiating cells (18), while previous microarray results have indicated that miR-33a is upregulated in supraglottic carcinoma (19). In osteosarcoma (OS), miR-33a is upregulated in chemoresistant OS and promotes resistance of OS cells to cisplatin through downregulation of the transcription factor, Twist (20). Furthermore, levels of miR-33a and miR-224 expression were elevated in steatotic chronic hepatitis $\mathrm{C}$ when compared to control liver tissue (21), and miR-33a in liver 
tissue has been found to significantly increase in a fibrosis progression-dependent manner (22). Collectively, these data indicate an oncogenic role of miR-33a, though its clinical significance and potential roles in HCC remain unknown.

Therefore, the present study investigated the effects of miR-33a and its underlying mechanisms of action in HCC using BrdU and apoptosis assays as well as dual luciferase reporter assays.

\section{Materials and methods}

Human tissues and cell culture. A total of 86 individual primary HCC tissues were collected between January 2010 and January 2012 from patients at The First Affiliated Hospital of Xi'an Jiaotong University (Xi'an, China). Patients were monitored for a median time of 31.6 months (range, 2-60 months). Clinical features of the 86 patients are listed in Table I. Age, gender, HBV infection, serum AFP level, tumor size and number of tumor nodules were measured prior to surgery, while other parameters were collected after surgery. Clinical specimens were immediately snap-frozen in liquid nitrogen prior to histological examination. Exclusion criteria included patients who had received chemotherapy or embolization prior to surgical resections. Samples were attained after obtaining informed consent from all patients and all protocols in the present study were approved by the Medicine Ethics Committee of Xi'an Jiaotong University in accordance with the Declaration of Helsinki (as revised in Tokyo 2004) (23).

Human HCC cell lines, HepG2 and Huh7 (Shanghai Institute of Biochemistry and Cell Biology, Chinese Academy of Sciences, Shanghai, China), were cultured in complete Dulbecco's modified Eagle's medium (Biosera, Inc., Villebon sur Yvette, France) supplemented with $10 \%$ fetal bovine serum (Biosera, Inc.), 100 units $/ \mathrm{ml}$ penicillin and $100 \mu \mathrm{g} / \mathrm{ml}$ streptomycin (Sigma-Aldrich, Merck KGaA, Darmstadt, Germany). Cell lines were cultured in a humidified atmosphere in a 5\% $\mathrm{CO}_{2}$ incubator at $37^{\circ} \mathrm{C}$ for 2-3 days and collected for further analyses.

RNA isolation and reverse transcription-quantitative polymerase chain reaction ( $R T-q P C R)$. Total RNA was isolated from frozen tissues or cultured HCC cells using TRIzol reagent (Invitrogen; Thermo Fisher Scientific, Inc., Waltham, MA, USA) according to the manufacturer's instructions. Quantification of miR-33a was performed using a TaqMan MicroRNA Assay kit (Applied Biosystems; Thermo Fisher Scientific, Inc.) and U6 small nuclear RNA was used as an endogenous control by determining the fold-change in miR-33a expression relative to U6 expression. For PPAR $\alpha$ quantification, cDNA was synthesized using Taqman RT reagents (Applied Biosystems; Thermo Fisher Scientific, Inc.). Total RNA ( $2 \mu \mathrm{g})$ was reverse transcribed at $37^{\circ} \mathrm{C}$ for $15 \mathrm{~min}$, and cDNA was incubated at $85^{\circ} \mathrm{C}$ for $5 \mathrm{sec}$ to inactivate the reverse transcriptase. cDNA ( $2 \mu \mathrm{l}$ ) was used for the qPCR, which was performed using a SYBR Premix Ex Taq II Perfect Real Time kit (Takara Bio, Inc., Otsu, Japan) in the ABI PRISM 7300 Sequence Detection system (Applied Biosystems; Thermo Fisher Scientific, Inc.). The reactions were incubated at $95^{\circ} \mathrm{C}$ for $60 \mathrm{sec}$, followed by 40 cycles of $95^{\circ} \mathrm{C}$ for $5 \mathrm{sec}$ and $60^{\circ} \mathrm{C}$ for $34 \mathrm{sec}$. Expression of PPAR $\alpha$ mRNA was normalized to that of GAPDH and the primer sequences were as follows: For PPAR $\alpha$ forward, 5'-ACT GTT GCA AGA GAT CTA CAG AG-3' and reverse, 5'-TTG TCT GTC ACT GTC TGA ATC C-3' and for GAPDH forward, 5'-AAC TTT GGC ATT GTG GAA GG-3' and reverse, 5'-ACA CAT TGG GGG TAG GAA CA-3'. All samples were normalized to internal controls and fold changes were calculated based on relative quantification using the $2^{-\Delta \Delta \mathrm{Cq}}$ method (24).

Cell transfection. Overexpression and inhibition of miR-33a in Huh7 and HepG2 cells, respectively, was established using miRNA vectors obtained from GeneCopoeia, Inc. (Rockville, MD, USA). In accordance with the manufacturer's instructions for Lipofectamine 2000 (Invitrogen; Thermo Fisher Scientific, Inc.), Huh7 cells at $75 \%$ confluence were transfected with an miR-33a expression vector (HmiR0366-MR03) or an miRNA scrambled control vector (CmiR0001-MR03), and HepG2 cells were transfected with an miR-33a inhibitory vector (HmiR-AN0429-AM03B) or a negative non-coding vector (CmiR-AN0001-SN). The efficacy of miR-33a or anti-miR-33a vector transfection was assessed by RT-qPCR as outlined above. The primer sequences used for miR-33a were as follows: forward, 5'-CGC GCG TGC ATT GTA GTT G-3' and reverse, 5'-CAC CAG GGT CCG AGG T-3' and stem loop primer, 5'-TGG ATA TCC ACA CCA GGG TCC GAG GTA TTC GGT GTG GAT ATC CAT GCA ATG-3'.

Cell proliferation and apoptosis assays. For the proliferation assay, transfected HCC cells were seeded into 96-well plates $\left(1 \times 10^{3}\right.$ cells/well $)$ and incubated at $37^{\circ} \mathrm{C}$. At $48 \mathrm{~h}$ post-transfection, the proliferative ability of $\mathrm{HCC}$ cells was assessed using a 5-bromo-2-deoxyuridine (BrdU) Cell Proliferation ELISA kit (Roche Diagnostics, Indianapolis, IN, USA), according to the manufacturer's instructions. For the apoptosis assay, HCC cells were seeded into 6 -well plates $\left(6 \times 10^{4}\right.$ cells/well) and incubated at $37^{\circ} \mathrm{C}$. At $48 \mathrm{~h}$ post-transfection, an Annexin-V-FLUOS Staining kit (Roche Diagnostics) was used to determine the percentage of apoptotic cells by flow cytometry, according to the manufacturer's instructions. Flow cytometric analysis was conducted using fluorescence-activated cell sorting Calibur (BD Biosciences, San Jose, CA, USA) and Cell Quest Pro v.4.0.2 software (BD Biosciences). Similar results were obtained in three independent experiments performed in duplicate.

Dual luciferase reporter assay. A dual luciferase reporter assay was performed to determine whether PPAR $\alpha$ was a downstream target gene of miR-33a in HCC cells. Briefly, the 3'-UTR sequence of PPAR $\alpha$, which was predicted to interact with miR-33a using two publicly available databases (TargetScan 6.2, targetscan.org; miRanDa, microrna.org), or a mutated sequence within the predicted sites were synthesized (GeneChem Co., Ltd., Shanghai, China) and inserted into the $\mathrm{XbaI}$ and FseI restriction sites of a pGL3 control vector (luciferase reporter vector; Promega Corporation, Madison, WI, USA) downstream of a luciferase minigene, as previously reported (25). These constructs were named as wild-type (wt) PPAR $\alpha-3$ 'UTR or mutant (mt) PPAR $\alpha-3$ 'UTR, respectively. For the reporter assay, HepG2 cells that were seeded into 96-well plates $\left(5 \times 10^{3}\right.$ cells/well) were cultured in complete Dulbecco's 
Table I. Clinical association analysis of miR-33a expression in HCC.

\begin{tabular}{|c|c|c|c|c|}
\hline \multirow[b]{2}{*}{ Clinicopathological features } & \multirow{2}{*}{$\begin{array}{l}\text { No. of patients } \\
\qquad(\mathrm{n}=86)\end{array}$} & \multicolumn{2}{|c|}{ No. of patients $(\mathrm{n}=86)$} & \multirow[b]{2}{*}{ P-value } \\
\hline & & Low miR-33a & High miR-33a & \\
\hline \multicolumn{5}{|l|}{ Age (years) } \\
\hline$<50$ & 27 & 16 & 11 & 0.245 \\
\hline$\geq 50$ & 59 & 27 & 32 & \\
\hline \multicolumn{5}{|l|}{ Gender } \\
\hline Male & 69 & 34 & 35 & 0.787 \\
\hline Female & 17 & 9 & 8 & \\
\hline \multicolumn{5}{|l|}{$\mathrm{HBV}$} \\
\hline Absent & 30 & 14 & 16 & 0.651 \\
\hline Present & 56 & 29 & 27 & \\
\hline \multicolumn{5}{|l|}{ Serum AFP level, ng/ml } \\
\hline$<20$ & 20 & 11 & 9 & 0.610 \\
\hline$\geq 20$ & 66 & 32 & 34 & \\
\hline \multicolumn{5}{|l|}{ Tumor size, $\mathrm{cm}$} \\
\hline$<5$ & 30 & 20 & 10 & 0.024 \\
\hline$\geq 5$ & 56 & 23 & 33 & \\
\hline \multicolumn{5}{|l|}{ No. of tumor nodules } \\
\hline 1 & 66 & 35 & 31 & 0.307 \\
\hline$\geq 2$ & 20 & 8 & 12 & \\
\hline \multicolumn{5}{|l|}{ Cirrhosis } \\
\hline Absent & 37 & 22 & 15 & 0.127 \\
\hline Present & 49 & 21 & 28 & \\
\hline \multicolumn{5}{|l|}{ Venous infiltration } \\
\hline Absent & 42 & 23 & 19 & 0.388 \\
\hline Present & 44 & 20 & 24 & \\
\hline \multicolumn{5}{|l|}{ Edmondson-Steiner grading } \\
\hline $\mathrm{I}+\mathrm{II}$ & 49 & 31 & 18 & 0.005 \\
\hline III+IV & 37 & 12 & 25 & \\
\hline \multicolumn{5}{|l|}{ TNM tumor stage } \\
\hline $\mathrm{I}+\mathrm{II}$ & 61 & 35 & 26 & 0.033 \\
\hline III+IV & 25 & 8 & 17 & \\
\hline
\end{tabular}

HCC, hepatocellular carcinoma; HBV, hepatitis B virus; AFP, $\alpha$-fetoprotein; TNM, tumor-node-metastasis.

modified Eagle medium (Biosera, Inc.) supplemented with $10 \%$ fetal bovine serum (Biosera, Inc.) at $37^{\circ} \mathrm{C}$ and co-transfected with miRNA mimics or inhibitors as outlined above, the above constructs and Renilla plasmid (Promega Corporation) using FuGENE HD Transfection Reagent (Promega Corporation), according to the manufacturer's protocol. At $48 \mathrm{~h}$ post-transfection, cells were harvested and Renilla and firefly luciferase activities were quantified using a Dual Luciferase Assay system (Promega Corporation), according to the manufacturer's protocol. Firefly luciferase activity was normalized to that of Renilla luciferase. Results were obtained from three independent experiments performed in triplicate.

Immunoblotting. HCC cells were lysed in radioimmunoprecipitation assay buffer (50 mM Tris pH 7.5, $150 \mathrm{mM}$ sodium chloride, $1 \%$ Triton $\mathrm{X}-100,5 \mathrm{mM}$ ethylenediaminetetraacetic acid) at $4^{\circ} \mathrm{C}$ for $1 \mathrm{~h}$, then insoluble material was removed by centrifugation at $12,000 \times \mathrm{g}$ for $10 \mathrm{~min}$. A total of $30 \mu \mathrm{g}$ of the resulting protein samples (per lane) were separated by $4-12 \%$ SDS-PAGE and transferred onto a nitrocellulose membrane. Blots were then incubated with primary antibodies against PPAR $\alpha$ (sc-398394; 1:1,000; Santa Cruz Technology, Inc., Santa Cruz, CA, USA) and GAPDH (5174; 1:1,500; Cell Signaling Technology, Inc., Danvers, MA, USA) at $4^{\circ} \mathrm{C}$ for at least $12 \mathrm{~h}$. After three washes with Tris-buffered saline-Tween-20, blots were incubated with horseradish peroxidase-conjugated goat anti-mouse (sc-2005; 1:5,000; Santa Cruz Technology, Inc.) or anti-rabbit secondary antibodies (1662408; 1:10,000; Bio-Rad Laboratories, Inc., Hercules, CA, USA) at room temperature for $2 \mathrm{~h}$, detected using a Bio-Rad Gel imaging system and quantified using Quantity One v.4.1 software (both from Bio-Rad Laboratories, Inc.). 
A

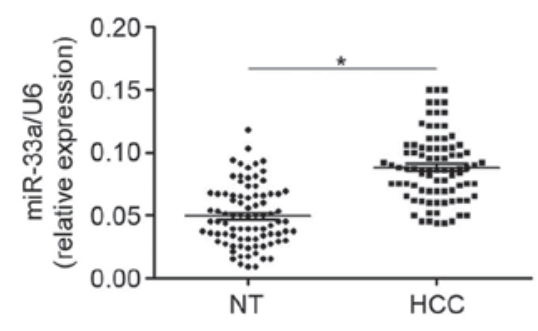

B

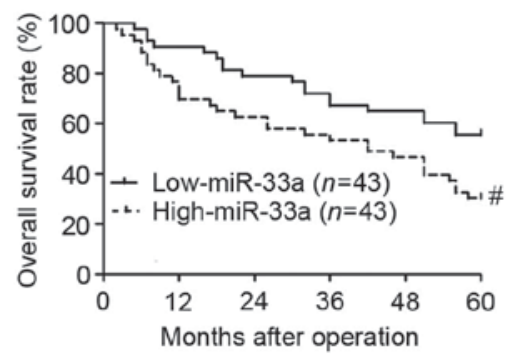

C

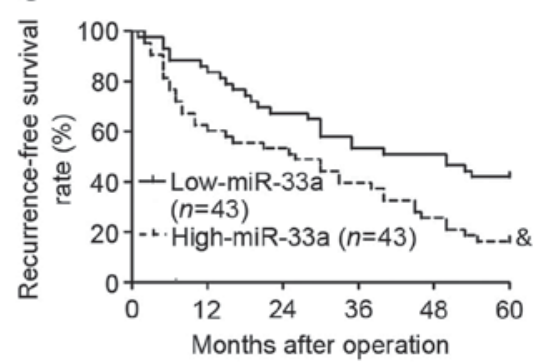

Figure 1. Expression and prognostic value of miR-33a in HCC. (A) Levels of miR-33a expression in HCC tissues relative to matched adjacent NT tissues obtained from $86 \mathrm{HCC}$ patients. (B) Overall survival rate of patients with high vs. low levels of miR-33a expression. (C) Recurrence-free survival rate of patients with high vs. low levels of miR-33a expression. The median level of miR-33a expression in the 86 HCC samples, detected by reverse transcription-quantitative polymerase chain reaction, was used as a cutoff value to define high and low miR-33a expression. ${ }^{*} \mathrm{P}<0.05$, vs. matched adjacent $\mathrm{NT}$ tissue, ${ }^{\prime} \mathrm{P}=0.015$ and ${ }^{\&} \mathrm{P}=0.008$ vs. patients with low miR-33a expression. miR-33a, microRNA-33a; HCC, hepatocellular carcinoma; NT, non-tumor; U6, small nuclear RNA.

Statistical analysis. Data are expressed as the mean \pm standard error of the mean. Group comparisons were conducted using a two-sample t-test or one-way analysis of variance (multiple comparisons). Categorical variables were compared using $\chi^{2}$ analysis or Fisher's exact test. Kaplan-Meier analysis was used to analyze overall survival and recurrence-free survival. SPSS 13.0 (SPSS, Inc., Chicago, IL, USA) and GraphPad Prism 5.0 software (GraphPad Software, Inc., La Jolla, CA, USA) were used for statistical analysis and $\mathrm{P}<0.05$ (two-tailed) was considered to indicate a statistically significant difference.

\section{Results}

Increased miR-33a expression in HCC correlates with adverse clinical features and poor prognosis. To elucidate the expression status and clinical significance of miR-33a in HCC, the levels of miR-33a were measured in HCC tissues and matched adjacent non-tumor tissues from $86 \mathrm{HCC}$ patients. It was observed that levels of miR-33a were significantly higher in HCC tissues relative to adjacent non-tumor tissues $(\mathrm{P}<0.05$; Fig. 1A). The clinical significance of miR-33a expression in HCC patients was subsequently investigated. Expression of miR-33a in HCC patients was determined to be low $(n=43)$ or high $(n=43)$ according to a cutoff value, which was defined as the median level of miR-33a in the patient cohort (0.087). As depicted in Table I, high levels of miR-33a expression were significantly correlated with larger tumor size $(\mathrm{P}=0.024)$, higher Edmondson-Steiner grading (poor differentiation; $\mathrm{P}=0.005)$ and higher tumor-node-metastasis tumor stage $(\mathrm{P}=0.033)$. Furthermore, a Kaplan-Meier analysis demonstrated that patients with high levels of miR-33a exhibited significant decreases in overall survival rate $(\mathrm{P}=0.015$; Fig. $1 \mathrm{~B})$ and recurrence-free survival rate $(\mathrm{P}=0.008$; Fig. $1 \mathrm{C})$. These results suggest that miR-33a serves an oncogenic role and may be a prognostic indicator in $\mathrm{HCC}$.

miR-33a induces proliferation and inhibits apoptosis in HCC cells. As increased proliferation and reduced apoptosis are key hallmarks of cancer cells (26), the oncogenic effects of miR-133a were subsequently determined by evaluating its effects on the proliferation and apoptosis of HCC cells. The
HCC cell line Huh7 was transfected with an miR-33a expression vector or an miR control vector. As depicted in Fig. 2A, miR-33a expression was significantly upregulated in Huh7 cells transfected with the miR-33a expression vector, relative to cells transfected with the miR control vector $(\mathrm{P}<0.05)$. Subsequently, a BrdU incorporation assay indicated that forced expression of miR-33a in Huh7 cells led to a significant increase in cellular proliferation $(\mathrm{P}<0.05$; Fig. $2 \mathrm{~B})$. In addition, an Annexin V/propidium iodide double staining assay demonstrated that the rate of apoptosis was significantly decreased in Huh7 cells overexpressing miR-33a $(\mathrm{P}<0.05$; Fig. 2C). By contrast, transfection of the HCC cell line HepG2 with miR-33a inhibitors resulted in significantly decreased miR-33a expression, relative to cells transfected with a negative control vector $(\mathrm{P}<0.05$; Fig. $3 \mathrm{~A})$. In turn, miR-33a downregulation lead to significantly decreased proliferation $(\mathrm{P}<0.05$; Fig. 3B) and increased apoptosis $(\mathrm{P}<0.05$; Fig. $3 \mathrm{C})$ in HepG2 cells. Collectively, these results indicate miR-33a may promote the development and progression of HCC by potentiating proliferation and inhibiting apoptosis of $\mathrm{HCC}$ cells.

PPAR $\alpha$ is a direct downstream target of miR-33a in HCC cells. To identify the underlying mechanisms by which miR-33a exerts its potential oncogenic effects in HCC cells, two publicly available databases, TargetScan 6.2 (www. targetscan.org) and miRanDa (www.microrna.org), were used to predict the target sequences of miR-33a. PPAR $\alpha$, which is considered to be a key regulator of HCC cell proliferation and apoptosis (27), was identified as a miR-33a target. As depicted in Fig. 4A, the 3'-UTR of PPAR $\alpha$ mRNA contains a complementary sequence for miR-33a binding, suggesting that PPAR $\alpha$ is a direct downstream target of miR-33a. Dual-luciferase reporter gene assays were subsequently performed to confirm whether miR-33a targets the 3'-UTR of PPAR $\alpha$ mRNA, using wild type (wt) and mutant (mt) PPAR $\alpha-3$ 'UTRs (Fig. 4A). As shown in Fig. 4B, overexpression of miR-33a in HepG2 cells significantly inhibited the luciferase activity of PPAR $\alpha$ expressing a wt 3'-UTR $(\mathrm{P}<0.05)$, while having no effect on that of mt PPAR $\alpha-3^{\prime}$ UTR. Accordingly, downregulation of miR-33a in HepG2 cells lead to significantly increased 
A

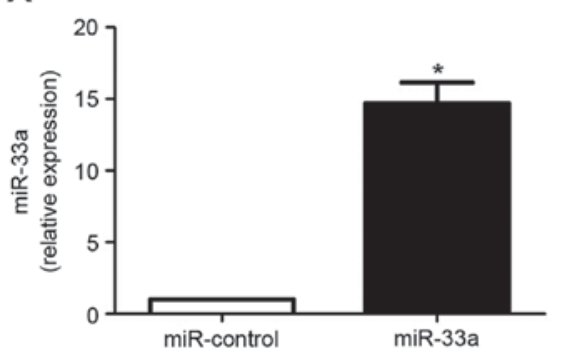

C

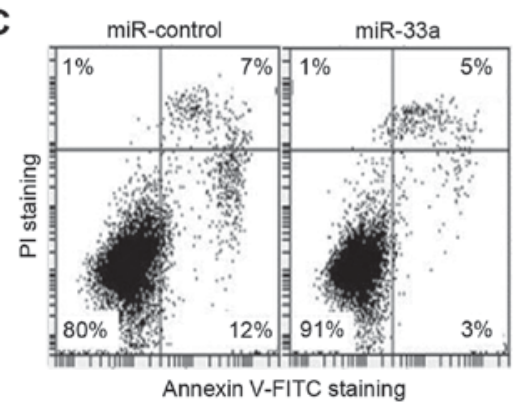

B
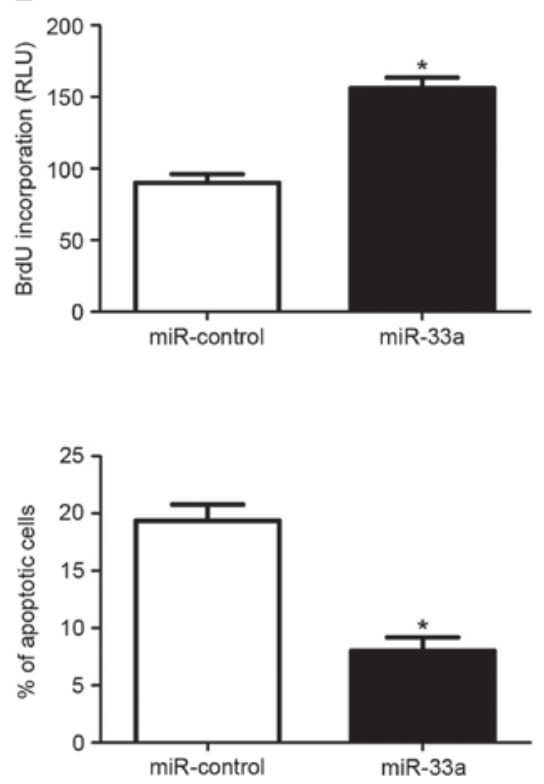

Figure 2. Overexpression of miR-33a promotes proliferation and reduces apoptosis in Huh7 cells. (A) Effects of transfection with miR-33a on the level of miR-33a expression in Huh7 cells. (B) BrdU incorporation assay demonstrating the proliferative capacity of Huh7 cells following upregulation of miR-33a. (C) An Annexin V/PI double staining assay demonstrating the effects of miR-33a overexpression in Huh7 cells on the apoptotic rate of cells. Three independent experiments were performed for each assay. Right upper quadrant displays late apoptotic cells and right lower quadrant displays early apoptotic cells. "P $<0.05$ vs. cells transfected with miR control vector. miR-33a, microRNA-33a; Huh7; hepatocellular carcinoma cell line; BrdU, bromodeoxyuridine; PI, propidium iodide; FITC, fluorescein isothiocyanate.

A

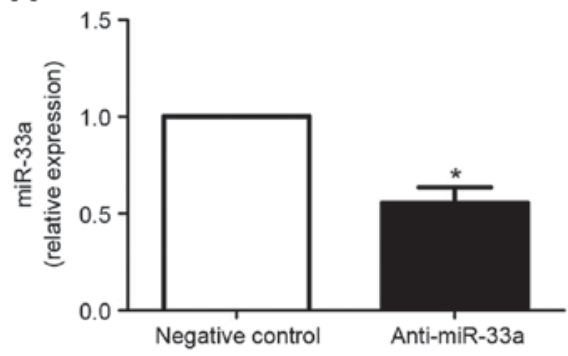

C

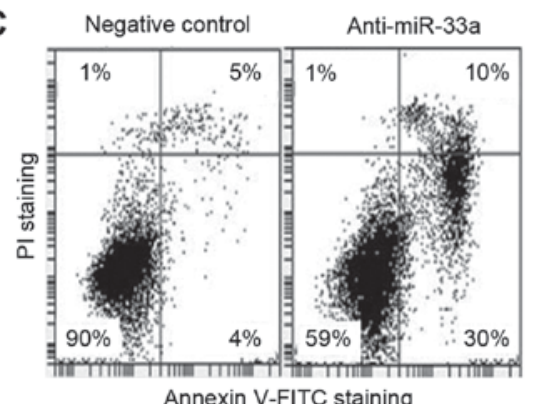

B
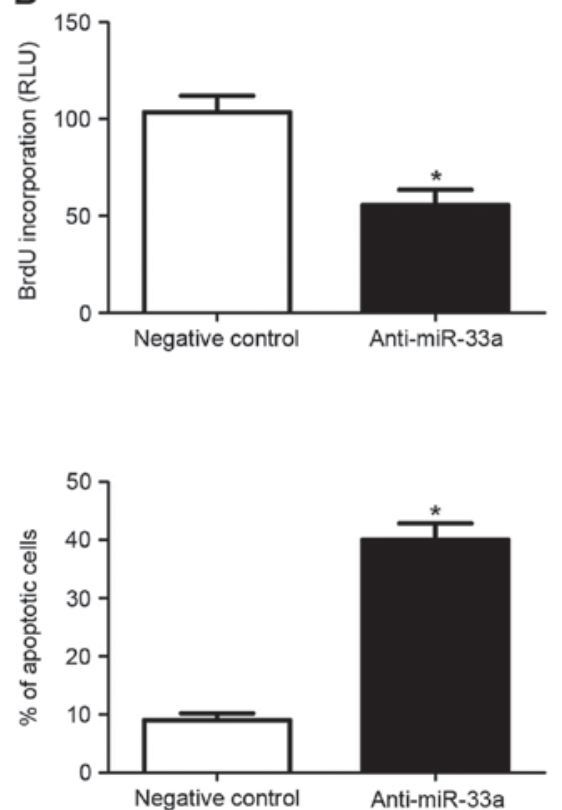

Figure 3. Down-regulation of miR-33a inhibits proliferation and increases apoptosis in HepG2 cells. (A) Transfection with miR-33a inhibitors significantly decreased the level of miR-33a expression in HepG2 cells. (B) A BrdU incorporation assay demonstrated that the proliferative capacity of HepG2 cells was decreased following downregulation of miR-33a in HepG2 cells. (C) An Annexin V/PI double staining assay demonstrated that inhibition of miR-33a in HepG2 cells significantly increased the apoptotic rate of cells. Right upper quadrant displays late apoptotic cells and right lower quadrant displays early apoptotic cells. Three independent experiments were performed for each assay. "P<0.05 vs. cells transfected with miR control vector. miR-33a, microRNA-33a; HepG2; hepatocellular carcinoma cell line; BrdU, bromodeoxyuridine; PI, propidium iodide; FITC, fluorescein isothiocyanate.

luciferase activity of wt PPAR $\alpha-3^{\prime} \mathrm{UTR}(\mathrm{P}<0.05)$, while having no significant effect on that of mt PPAR $\alpha-3$ 'UTR. These results indicate that PPAR $\alpha$ is a direct downstream target of miR-33a.
miR-33a regulates the expression of PPAR in HCC cells. RT-qPCR and western blot analysis were subsequently performed to determine whether miR-33a regulates the expression of PPAR $\alpha$ in HCC cells. It was observed that overexpression 
A

\begin{tabular}{|c|c|c|}
\hline $\begin{array}{l}\text { Mature miR-33a } \\
\text { nt (284-290) }\end{array}$ & $3^{\prime}$ & $\begin{array}{r}\text { ACGUUACGUUGAUGUUACGUG } \\
|||||| \mid\end{array}$ \\
\hline wtPPARa-3' UTR & 5 & . UCACCCGAUGUUAAUCAAUGCAC \\
\hline mt PPARa-3' UTR & 5 & $\ldots$ UCACCCGAUGUUAAUGAUUCCUC \\
\hline
\end{tabular}

B

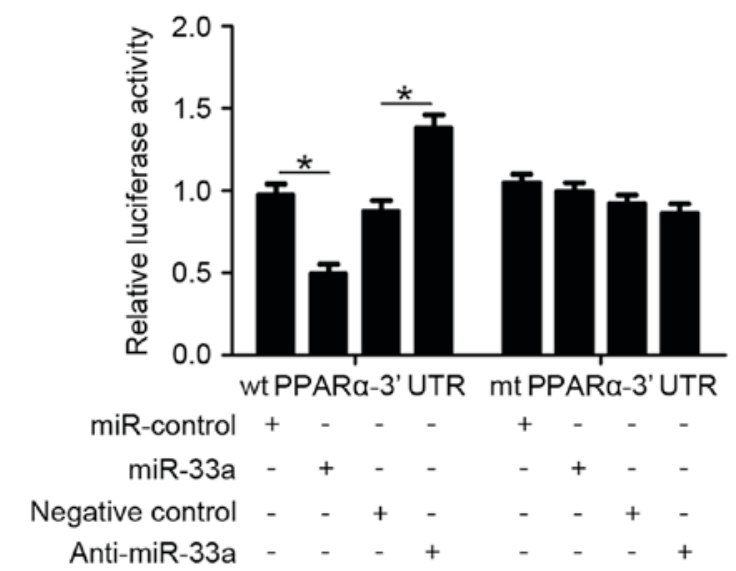

Figure 4. PPAR $\alpha$ is a direct downstream target of miR-33a in HCC cells. (A) A complementary sequence for miR-33a was identified in the 3'-UTR of PPAR $\alpha$. Dual-luciferase reporter gene assays were subsequently performed to confirm whether miR-33a targets the 3 '-UTR of PPAR $\alpha$ mRNA, using the wt and mt PPAR $\alpha-3$ 'UTR sequences shown. (B) Effects of overexpression of miR-33a on the luciferase activity of wt PPAR $\alpha-3$ '-UTR and mt PPAR $\alpha-3$ '-UTR. Three independent experiments were performed. "P<0.05. miR-33a, microRNA-33a; nt, nucleotides; wt, wild type; mt, mutant; PPAR $\alpha$, peroxisome proliferator-activated receptor- $\alpha$; UTR, untranslated region.

A

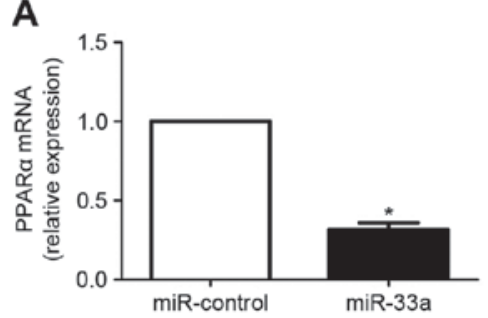

C

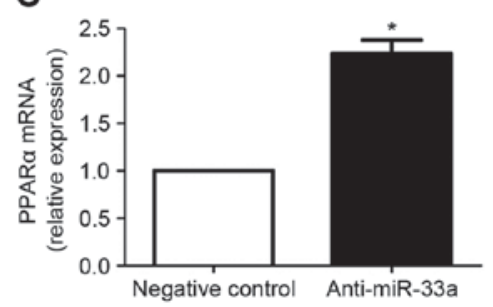

B
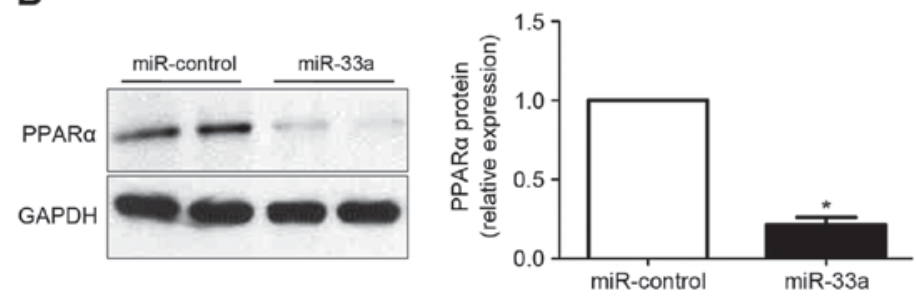

D
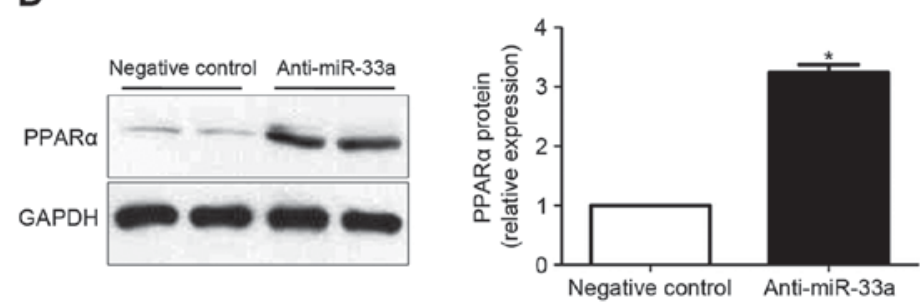

Figure 5. miR-33a regulates the expression of PPAR $\alpha$ in HCC cells. (A) RT-qPCR and (B) western blot analysis of PPAR $\alpha$ expression in Huh7 cells transfected with miR-33a mimic or miR control vectors. (C) RT-qPCR and (D) western blot analysis of PPAR $\alpha$ expression in HepG2 cells transfected with miR-33a inhibitor or negative control vectors. PPAR $\alpha$ expression levels are relative to GAPDH for both the RT-qPCR and western blot data. Three independent experiments were performed. "P<0.05 vs. respective control transfections. miR-33a, microRNA-33a; PPAR $\alpha$, peroxisome proliferator-activated receptor- $\alpha$; RT-qPCR, reverse transcription-quantitative polymerase chain reaction.

of miR-33a in Huh7 cells significantly decreased the levels of PPAR $\alpha$ mRNA ( $\mathrm{P}<0.05$; Fig. 5A). Results of western blot analysis also demonstrated that the levels of PPAR $\alpha$ protein was significantly reduced following forced expression of miR-33a $(\mathrm{P}<0.05$; Fig. 5B). By contrast, downregulation of miR-33a in HepG2 cells lead to significantly increased PPAR $\alpha$ expression at the mRNA $(\mathrm{P}<0.05$; Fig. $5 \mathrm{C})$ and protein $(\mathrm{P}<0.05$, Fig. 5D) levels.

\section{Discussion}

miRNAs regulate gene expression at the post-transcriptional level and have been demonstrated to participate in numerous biological processes, including embryogenesis, differentiation, morphogenesis and tumorigenesis $(1,3,4,28)$. In the last two decades, studies have investigated the potential roles of miRNAs in cancer. It has been indicated that miRNAs 
may have oncogenic or tumor-suppressive effects in human malignancies and may also serve as promising biomarkers and therapeutic targets in the diagnosis and treatment of cancer $(3,29)$. miR-33a is an established regulator of glucose and cholesterol metabolism $(14,30)$ and has been demonstrated to be an active regulator in the pathogenesis of various human cancers, including pancreatic cancer $(15,16)$, lung cancer (17), glioma (18), osteosarcoma (31) and colon cancer (32). In the present study, significant overexpression of miR-33a was confirmed in HCC tissues. In turn, increased expression of miR-33a was associated with adverse clinical features and a poor prognosis for $\mathrm{HCC}$ patients. These results indicate that miR-33a may serve an oncogenic role in HCC and as a potential biomarker for the diagnosis and prognostic prediction of HCC.

Functionally, miR-33a is a key regulator of cholesterol metabolism through its manipulation of adenosine triphosphate-binding cassette transporter A1 levels (13). In addition, it regulates glucose metabolism through targeting of phosphoenolpyruvate carboxykinase and glucose-6-phosphatase (14). However, miR-33a is also implicated in numerous aspects of cancer biology. In pancreatic cancer cells, miR-33a has been demonstrated to enhance gemcitabine sensitivity (16), while in lung cancer, the miRNA acts a bone metastasis suppressor through its targeting of parathyroid hormone related protein (17). It has also been suggested that miR-33a may promote the self-renewal of glioma-initiating cells (18). In the present study, gain- and loss-of-function experiments demonstrated that miR-33a may promote the growth of HCC by potentiating proliferation and inhibiting apoptosis of HCC cells. Specifically, overexpression of miR-33a promoted proliferation and inhibited apoptosis of Huh7 cells, while inhibition of miR-33a decreased proliferation and increased apoptosis of HepG 2 cells. Therefore, these results indicate that miR-33a may promote the development and progression of HCC, at least in part through modulation of cell proliferation and apoptosis.

PPAR $\alpha$ is a member of the nuclear hormone receptor superfamily and participates in the metabolism of glucose and lipids (33). In addition, it has been identified as a tumor suppressor in colorectal carcinoma (34) and ovarian cancer (35). Regarding HCC, a previous study has demonstrated that PPAR $\alpha$ exerted anti-tumorigenic effects in HCC cells through modulation of nuclear factor- $\kappa \mathrm{B}$ signaling (27). It has also been observed in HCC cells that ectopic expression of PPAR $\alpha$ significantly suppressed proliferation while inducing apoptosis (27). In the present study, a complementary sequence for miR-33a was identified in the 3'-UTR of PPAR $\alpha$. In turn, alterations in miR-33a expression led to significant changes in luciferase activity of wt PPAR $\alpha-3$ '-UTR, while having no influence on that of mt PPAR $\alpha-3$-UTR. Furthermore, ectopic expression of miR-33a significantly reduced the expression of PPAR $\alpha$, while downregulation of miR-33a led to a significant increase in PPAR $\alpha$ expression. Collectively, these data indicate that PPAR $\alpha$ is a direct downstream target of miR-33a in HCC cells. Thus, the regulatory effects of miR-33a on HCC cell proliferation and apoptosis may be due to its targeting of PPAR $\alpha$.

In conclusion, the present study demonstrated that miR-33a is overexpressed in HCC tissues, with elevated expression of miR-33a correlated with adverse clinical features and poor prognosis in HCC. Functional experiments also demonstrated that miR-33a may promote cell growth by modulating the proliferation and apoptosis of HCC cells. Furthermore, PPAR $\alpha$ was verified to be a direct downstream target of miR-33a. Collectively, these data suggest that miR-33a may be a novel clinical biomarker for the diagnosis and prognosis of HCC, as well as a potential therapeutic target for the treatment of HCC.

\section{References}

1. Yates LA, Norbury CJ and Gilbert RJ: The long and short of microRNA. Cell 153: 516-519, 2013.

2. He L and Hannon GJ: MicroRNAs: Small RNAs with a big role in gene regulation. Nat Rev Genet 5: 522-531, 2004.

3. Calin GA and Croce CM: MicroRNA signatures in human cancers. Nat Rev Cancer 6: 857-866, 2006.

4. Osman A: MicroRNAs in health and disease-basic science and clinical applications. Clin Lab 58: 393-402, 2012.

5. Rottiers V and Näär AM: MicroRNAs in metabolism and metabolic disorders. Nat Rev Mol Cell Biol 13: 239-250, 2012.

6. Forner A, Llovet JM and Bruix J: Hepatocellular carcinoma. Lancet 379: 1245-1255, 2012.

7. Yang N, Ekanem NR, Sakyi CA and Ray SD: Hepatocellular carcinoma and microRNA: New perspectives on therapeutics and diagnostics. Adv Drug Deliv Rev 81: 62-74, 2015.

8. Dhanasekaran R, Limaye A and Cabrera R: Hepatocellular carcinoma: Current trends in worldwide epidemiology, risk factors, diagnosis, and therapeutics. Hepat Med 4: 19-37, 2012.

9. Aravalli RN, Steer CJ and Cressman EN: Molecular mechanisms of hepatocellular carcinoma. Hepatology 48: 2047-2063, 2008.

10. Tanaka S and Arii S: Molecular targeted therapies in hepatocellular carcinoma. Semin Oncol 39: 486-492, 2012.

11. Cirera-Salinas D, Pauta M, Allen RM, Salerno AG, Ramírez CM, Chamorro-Jorganes A, Wanschel AC, Lasuncion MA, Morales-Ruiz M, Suarez Y, et al: Mir-33 regulates cell proliferation and cell cycle progression. Cell Cycle 11: 922-933, 2012.

12. Li T, Francl JM, Boehme S and Chiang JY: Regulation of cholesterol and bile acid homeostasis by the cholesterol $7 \alpha$-hydroxylase/steroid response element-binding protein 2/microRNA-33a axis in mice. Hepatology 58: 1111-1121, 2013.

13. Najafi-Shoushtari SH, Kristo F, Li Y, Shioda T, Cohen DE, Gerszten RE and Näär AM: MicroRNA-33 and the SREBP host genes cooperate to control cholesterol homeostasis. Science 328: 1566-1569, 2010

14. Ramírez CM, Goedeke L, Rotllan N, Yoon JH, Cirera-Salinas D, Mattison JA, Suárez Y, de Cabo R, Gorospe M and Fernández-Hernando C: MicroRNA 33 regulates glucose metabolism. Mol Cell Biol 33: 2891-2902, 2013.

15. Liang C, Yu XJ, Guo XZ, Sun MH, Wang Z, Song Y, Ni QX, Li HY, Mukaida N and Li YY: MicroRNA-33a-mediated downregulation of Pim-3 kinase expression renders human pancreatic cancer cells sensitivity to gemcitabine. Oncotarget 6 : 14440-14455, 2015.

16. Liang C, Wang Z, Li YY, Yu BH, Zhang F and Li HY: miR-33a suppresses the nuclear translocation of $\beta$-catenin to enhance gemcitabine sensitivity in human pancreatic cancer cells. Tumour Biol 36: 9395-9403, 2015.

17. Kuo PL, Liao SH, Hung JY, Huang MS and Hsu YL: MicroRNA-33a functions as a bone metastasis suppressor in lung cancer by targeting parathyroid hormone related protein. Biochim Biophys Acta 1830: 3756-3766, 2013.

18. Wang H, Sun T, Hu J, Zhang R, Rao Y, Wang S, Chen R, McLendon RE, Friedman AH, Keir ST, et al: miR-33a promotes glioma-initiating cell self-renewal via PKA and NOTCH pathways. J Clin Invest 124: 4489-4502, 2014.

19. Zhang T, Han G, Wang Y, Chen K and Sun Y: MicroRNA expression profiles in supraglottic carcinoma. Oncol Rep 31: 2029-2034, 2014

20. Zhou Y, Huang Z, Wu S, Zang X, Liu M and Shi J: miR-33a is up-regulated in chemoresistant osteosarcoma and promotes osteosarcoma cell resistance to cisplatin by down-regulating TWIST. J Exp Clin Cancer Res 33: 12, 2014.

21. Lendvai G, Jármay K, Karácsony G, Halász T, Kovalszky I, Baghy K, Wittmann T, Schaff Z and Kiss A: Elevated miR-33a and miR-224 in steatotic chronic hepatitis $\mathrm{C}$ liver biopsies. World J Gastroenterol 20: 15343-15350, 2014. 
22. Huang CF, Sun CC, Zhao F, Zhang YD and Li DJ: miR-33a levels in hepatic and serum after chronic HBV-induced fibrosis. J Gastroenterol 50: 480-490, 2015.

23. World Medical Association: World Medical Association Declaration of Helsinki: Ethical principles for medical research involving human subjects. JAMA 310: 2191-2194, 2013.

24. Livak KJ and Schmittgen TD: Analysis of relative gene expression data using real-time quantitative PCR and the 2(-Delta Delta C (T)) Method. Methods 25: 402-408, 2001.

25. Shimono Y, Zabala M, Cho RW, Lobo N, Dalerba P, Qian D, Diehn M, Liu H, Panula SP, Chiao E, et al: Downregulation of miRNA-200c links breast cancer stem cells with normal stem cells. Cell 138: 592-603, 2009.

26. Hanahan D and Weinberg RA: Hallmarks of cancer: The next generation. Cell 144: 646-674, 2011

27. Zhang N, Chu ES, Zhang J, Li X, Liang Q, Chen J, Chen M, Teoh N, Farrell G, Sung JJ and Yu J: Peroxisome proliferator activated receptor alpha inhibits hepatocarcinogenesis through mediating NF- $\kappa$ B signaling pathway. Oncotarget 5: 8330-8340, 2014.

28. Lujambio A and Lowe SW: The microcosmos of cancer. Nature 482: 347-355, 2012.

29. Cho WC: MicroRNAs: Potential biomarkers for cancer diagnosis, prognosis and targets for therapy. Int J Biochem Cell Biol 42: $1273-1281,2010$

30. Dávalos A, Goedeke L, Smibert P, Ramírez CM, Warrier NP, Andreo U, Cirera-Salinas D, Rayner K, Suresh U, Pastor-Pareja JC, et al: $\mathrm{miR}-33 \mathrm{a} / \mathrm{b}$ contribute to the regulation of fatty acid metabolism and insulin signaling. Proc Natl Acad Sci USA 108: 9232-9237, 2011.
31. Zhou Y, Huang ZF, Wu S, Zang XF, Liu M and Shi J: miR-33a is up-regulated in chemoresistant osteosarcoma and promotes osteosarcoma cell resistance to cisplatin by down-regulating TWIST. J Exp Clin Canc Res 33: 12, 2014.

32. Ibrahim AF, Weirauch U, Thomas M, Grünweller A, Hartmann RK and Aigner A: MicroRNA replacement therapy for miR-145 and miR-33a is efficacious in a model of colon carcinoma. Cancer Res 71: 5214-5224, 2011.

33. Lefebvre P, Chinetti G, Fruchart JC and Staels B: Sorting out the roles of PPAR alpha in energy metabolism and vascular homeostasis. J Clin Invest 116: 571-580, 2006.

34. Grau R, Punzón C, Fresno M and Iñiguez MA: Peroxisomeproliferator-activated receptor alpha agonists inhibit cyclo-oxygenase 2 and vascular endothelial growth factor transcriptional activation in human colorectal carcinoma cells via inhibition of activator protein-1. Biochem J 395: 81-88, 2006.

35. Yokoyama Y, Xin B, Shigeto T, Umemoto M, Kasai-Sakamoto A, Futagami M, Tsuchida S, Al-Mulla F and Mizunuma H: Clofibric acid, a peroxisome proliferator-activated receptor alpha ligand, inhibits growth of human ovarian cancer. Mol Cancer Ther 6: 1379-1386, 2007. 